\title{
The earthquake-related disturbances in ionosphere and project of the first China seismo-electromagnetic satellite*
}

\author{
Xuhui Shen ${ }^{1, \star}$ Xuemin Zhang ${ }^{1}$ Lanwei Wang ${ }^{2}$ Huaran Chen ${ }^{3}$ \\ Yun $\mathrm{Wu}^{4}$ Shigeng Yuan $^{5}$ Junfeng Shen ${ }^{6}$ Shufan Zhao ${ }^{1}$ \\ Jiadong Qian ${ }^{1}$ and Jianhai Ding ${ }^{1}$ \\ ${ }^{1}$ Institute of Earthquake Science, China Earthquake Administration, Beijing 100036, China \\ ${ }^{2}$ Institute of Crustal Dynamics, China Earthquake Administration, Beijing 100085, China \\ ${ }^{3}$ Institute of Geophysics, China Earthquake Administration, Beijing 100081, China \\ ${ }^{4}$ Earthquake Administration of Hubei Province, Wuhan 430071, China \\ ${ }^{5}$ DFH Satellite Co. Ltd., Beijing 100094, China \\ ${ }^{6}$ State Key Laboratory of Geological Processes and Mineral Resources, Chinese University of \\ Geosciences, Beijing 100029, China
}

\begin{abstract}
Based on the case studies and statistical analysis of earthquake-related ionospheric disturbances mainly from DEMETER satellite, ground-based GPS and ionosounding data, this paper summarizes the statistical characteristics of earthquake-related ionospheric disturbances, including electromagnetic emissions, plasma perturbations and variation of energetic particle flux. According to the main results done by Chinese scientists, fusing with the existed study from global researches, seismo-ionospheric disturbances usually occurred a few days or hours before earthquake occurrence. Paralleling to these case studies, lithosphere-atmosphere-ionosphere (LAI) coupling mechanisms are checked and optimized. A thermo-electric model was proposed to explain the seismo-electromagnetic effects before earthquakes. A propagation model was put forward to explain the electromagnetic waves into the ionosphere. According to the requirement of earthquake prediction research, China seismo-electromagnetic satellite, the first space-based platform of Chinese earthquake stereoscopic observation system, is proposed and planned to launch at about the end of 2014. It focuses on checking the LAI model and distinguishing earthquake-related ionospheric disturbance. The preliminary design for the satellite will adopt CAST-2000 platform with eight payloads onboard. It is believed that the satellite will work together with the ground monitoring network to improve the capability to capture seismo-electromagnetic information, which is beneficial for earthquake monitoring and prediction researches.
\end{abstract}

Key words: seismo-ionospheric coupling; earthquake-related ionospheric disturbance; China seismoelectromagnetic satellite; lithosphere-atmosphere-ionosphere coupling model

CLC number: P351.72+1, P352.4 Document code: A

\section{Introduction}

An earthquake results from sudden release of energy in the crust. But its activities are under the

\footnotetext{
* Received 10 October 2011; accepted in revised form 2 November 2011; published 10 December 2011.

* Corresponding author. e-mail: shenxh@seis.ac.cn

(C) The Seismological Society of China and Springer-Verlag Berlin Heidelberg 2011
}

influence of the interaction of multi-layers of the Earth system. When an earthquake occurs, different phenomena are observed underground, on the surface, and in the space at the same time. Integration of the observations from multi-layers is very important for understanding the earthquake and earthquake prediction.

Electromagnetic field is one of the natural media to link the multi-layers in the Earth system. Electro- 
magnetic anomaly before earthquake can propagate into the ionosphere according to the coupling among lithosphere, atmosphere, and ionosphere. Lots of ionospheric disturbances related to earthquakes have been reported since the great earthquake in Alaska in 1964 (Davies and Baker, 1965; Gokhberg et al., 1983; Larkina et al., 1989; Parrot and Lefeuvre, 1989; Parrot et al., 1993; Parrot, 1995; Pulinets, 2004; Pulinets and Boyarchuk, 2004; Pulinets et al., 1994, 1998, 2010; Ruzhin and Larkina, 1996; Ruzhin et al., 1998; Isaev and Serebryakova, 2001; Chmyrev et al., 1997; Liu et al., 2000, 2001, $2004 \mathrm{a}, \mathrm{b})$. The documented reports show that there are obvious relationship between earthquake precursors and ionospheric disturbances. Some countries developed seismo-electromagnetic satellite mission to collect electromagnetic information related to earthquakes, such as COMPASS-2 in Russia, QUAKESAT-1 in America, SICH-1M in Ukraine, DEMETER in French.

China has built a large ground-based earthquake monitoring network, including electromagnetic observation, to mitigate and even to prevent losses from earthquake disasters. The observed data are mainly used to develop earthquake prediction methodologies and models. According to the project "National Middle-Long Term Plan for Earthquake Disaster Mitigation and Prevention (2006-2020)", space-based earthquake monitoring system is being proposed in the last years. By integrating the space and ground-based earthquake monitoring system, Chinese earthquake stereoscopic observation system is under developing. During the proposal of the first seismo-electromagnetic satellite in China, Chinese scientists made some collaborative researches with the scientists all of the word, especially those working for DEMETER mission (Cussac et al., 2006; Lagouttea et al., 2006). The topic includes case studies and statistical studies on ionospheric disturbances related to earthquakes, as well as possible mechanisms related to seismo-electromagnetic emission propagation into the ionosphere.

This paper mainly shows some new progresses in seismo-ionospheric coupling and new results of the studies about ionospheric disturbances related to earthquakes in China, and introduces the proposal of the first seismo-electromagnetic satellite in China based on the seismo-ionospheric researches.

\section{New understanding on theoreti- cal models of seismo-ionospheric coupling}

Based on the observations of earthquake activities, several models have been proposed to explain the mechanism of seismo-ionospheric coupling (Pulinets and Ouzounov, 2011). The main models include electromagnetic wave penetrating model (Molchanov et al., 1995), acoustic wave penetrating model (Hegai et al., 1997), electrical field and geochemistry model (Pulinets, 2004, 2009; Pulinets et al., 1997, 1998, 2000, 2010; Shalimov and Gokhberg, 1998; Sorokin et al., 2007; Molchanov et al., 2004; Klimenko et al., 2011).

To illustrate the mechanism of earthquake-related electromagnetic emission formation as well as the way of seismo-electromagnetic emission propagation into the ionosphere, we carried out some primary studies on thermo-electric model and electromagnetic full wave propagation model as following using physical modeling and computing techniques.

2.1 Thermo-electric model of seismoelectromagnetic effects before earthquakes

Most of the earthquakes occurred in the middle crust of the Earth where high temperature and high pressure condition exists. The materials of the Earth's crust usually behavior as semi-conductors because of their deformation while crystallizating. Thermo-electric model was proposed to explain seismo-electromagnetic effects before earthquakes, and to quantitatively describe the electromagnetic emissions during earthquake preparation (Shen et al., 2009, 2010b).

The thermo-electric coefficients of tens of thousand of samples, such as magnetite, pyrite, cassiterite, and arsenopyrite, were tested respectively by the thermoelectric instrument BHET-06. Results showed that the coefficient is a constant value of about -0.051 to -0.381 $\mathrm{mV} /{ }^{\circ} \mathrm{C}$. Because every mineral grain was tested randomly, the coefficient is independent of the crystallographic direction. It means the thermal voltage generated from a single magnetite crystal can be accumulated. As a result, a new thermo-electric field can arise when a gradient thermal field exists within the Earth's crust.

The thermo-electric effect of semi-conductor minerals was used to study the mechanism responsible for the presence of abnormal geo-electric fields during 
earthquake preparation and occurrence, because gradient thermal fields always exist before earthquakes. The possible presence of additional thermo-electric fields $(E)$ was calculated with

$$
E=-0.159 \frac{\sigma \Delta T \Phi \rho_{2}\left[\left(h^{2}-2 x^{2}\right) \cos \alpha+3 h x \sin \alpha\right]}{\rho_{1} \sqrt{\left(h^{2}+x^{2}\right)^{5}}},
$$

where $\sigma$ is thermo-electric coefficient of the minerals, $\Delta T$ is the temperature difference acting on it, $\Phi$ is a sectional area on a block of mineral vertically perpendicular to the direction of the thermal current, $\rho_{1}$ and $\rho_{2}$ are the resistivity of mineral and the crust, respectively, $h$ is embedded depth of mineral block, $\alpha$ is the angle created by the horizontal line and the line between the two poles of mineral block, and $x$ is the distance from the observation point to the projected center point of the magnetite block on the Earth's surface. The calculated additional thermo-electric field intensity is about several to thousands $\mathrm{mV} / \mathrm{km}$. This field is strong enough to cause obvious anomalies on the background of geo-electric field, which can be detected by geo-electric monitoring equipments.

In fact, minerals with semiconductor behavior are widespread in the crust. A variable thermal field usually accompanies earthquake formation and occurrence. The geo-electric field may be impacted by an additional thermo-electric field generated by the thermal-electric effect of magnetite during the earthquake formation and occurrence. Therefore, a hypothesis was proposed that geo-electric abnormities occurred during earthquakes

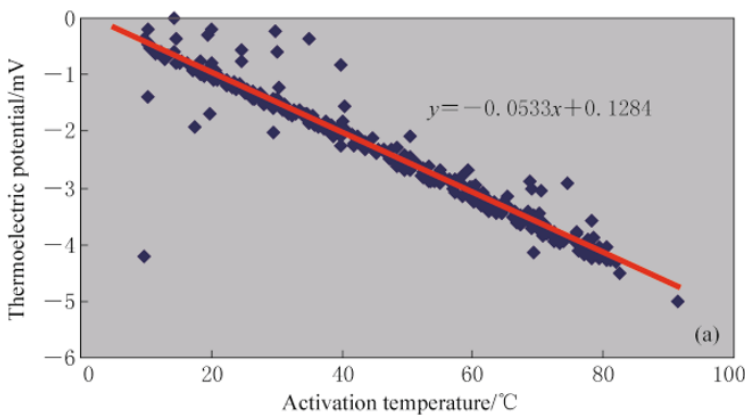

may be caused by the thermo-electric effect of the minerals (Figure 1).

The crustal minerals were further analyzed during the experiments. The results indicate that $90 \%$ of these minerals act as N-type semiconductor and about $10 \%$ acts as P-type semiconductor. It means that the thermo-electric coefficient should be negative for most of the crustal materials, while only $10 \%$ of them have positive thermo-electric coefficient (Figure 2).

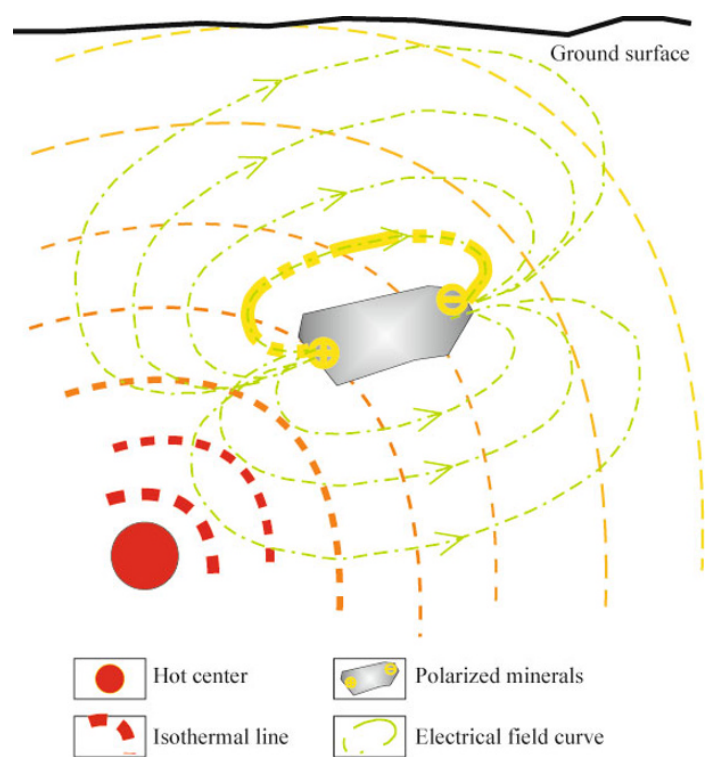

Figure 1 Thermo-electrical model of earthquake-related electromagnetic emission. After Shen et al. (2010a).

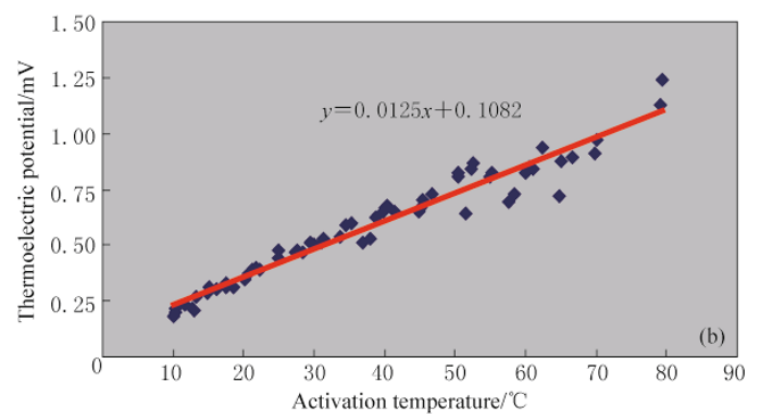

Figure 2 The different thermo-electric effects of typical N-type (a) and P-type semiconductors (b).

In 2004, Takeuchi et al. (2004) proposed the p-hole model for radiation of static electrical field while earthquake occurs, and gave a detail description on $\mathrm{H}^{+}$activation during strong tectonic activities and following these course, the additional geo-electrical field was triggered and then penetrated into the atmosphere and ionosphere. Based on our studies, it is reasonable to combine p-hole model and thermo-electric model to understand and explain the seismo-ionospheric disturbance in detail.

\subsection{Propagation model of electromagnetic waves into the ionosphere}

Additional electromagnetic emission may occur before earthquakes as mentioned above. How does the elec- 
tromagnetic wave propagate into the ionosphere? To unravel the mystery, we proposed an electromagnetic full wave propagation model to compute the capability of VLF waves into horizontal stratified ionosphere (Zhao et al., 2010).

Our basic idea is as following: assuming the altitude of $80 \mathrm{~km}$ as an interface of the waveguide, Earthionosphere waveguide model is used to calculate the nodal fields at the lower boundary of the ionosphere lower than $80 \mathrm{~km}$; full-wave method is employed to calculate the electromagnetic field distribution above 80 $\mathrm{km}$ numerically.
Coordinates used in the full wave calculation and

the Maxwell equations in the ionosphere are as follows:

$$
\begin{gathered}
\nabla \times \boldsymbol{H}=\mathrm{j} \omega \varepsilon_{0}(\boldsymbol{I}+\boldsymbol{M}) \bullet \boldsymbol{E}, \\
\nabla \times \boldsymbol{E}=-\mathrm{j} \omega \mu_{0} \boldsymbol{H},
\end{gathered}
$$

where, $\varepsilon_{0}, \mu_{0}$ and $\boldsymbol{I}$ denote the permittivity, the permeability of free space, and the unit matrix. The effect of ions on the wave propagation is ignored and only electron effect is considered, which is reasonable at VLF frequency band because wave frequency is much higher than ion gyro-frequency but equivalent to the electron gyro-frequency. The magnetic susceptibility matrix $\boldsymbol{M}$ is given by

$$
\boldsymbol{M}=-\frac{X}{U\left(U^{2}-y^{2}\right)}\left[\begin{array}{ccc}
U^{2}-l^{2} y^{2} & \mathrm{i} n y U-\ln y^{2} & -\mathrm{i} m y U-\ln y^{2} \\
-\mathrm{i} n y U-\ln y^{2} & U^{2}-m^{2} y^{2} & \mathrm{i} l y U-m n y^{2} \\
\mathrm{i} m y U-\ln y_{\alpha}^{2} & -\mathrm{i} l y U-m n y_{\alpha}^{2} & U^{2}-n^{2} y^{2}
\end{array}\right]
$$

with $U=1+\mathrm{i} Z, \quad Z=\nu / \omega, \quad X=\left(\omega_{p} / \omega\right)^{2}, \omega_{p}^{2}=e^{2} N / m \varepsilon_{0}$, $\omega_{h}=e B / m, Y=\left|\omega_{h} / \omega\right|$, where $\omega_{p}$ is electron plasma angular frequency, $\omega_{h}$ is electron gyro angular frequency, $e$ is electron charge $(\mathrm{C}), m$ is electron mass $(\mathrm{kg}), N$ is electron number density $\left(\mathrm{m}^{-3}\right), \nu$ is electron collision frequency.

The primary results are as following:

1) Left-handed polarization wave experiences the most severe attenuation in the D-region of the ionosphere, so it is called non-penetrating mode. Righthanded polarization wave can penetrate the D-region of the ionosphere, so it is called penetrating mode in the ionosphere.

2) The attenuation is very small for the waves having crossed the D-region.

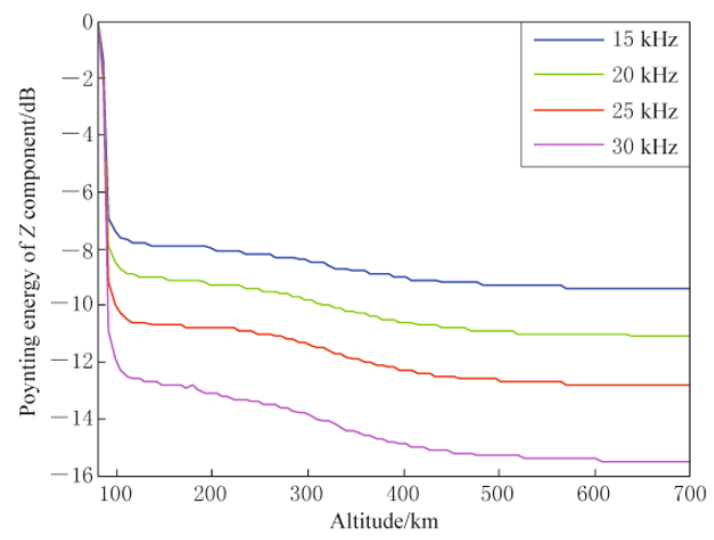

Figure 3 Variation of Poynting energy of $Z$ component with altitude for different frequencies.
3) The Poynting flux decreases with the wave frequency increasing, which means the lower frequency signal related to earthquake is easier to reach the sensors on the satellites (Figure 3 ).

4) The response in the ionosphere caused by ground VLF transmitter behaviors as concentric circles; the circles is asymmetrical from north to the south; multi-mode interferometer can be clearly seen; the center of these circles has a latitudinal displacement to the equator, the magnitude of the displacement is proportional to the latitude of the transmitter (Figure 4).

Based on the results mentioned above, primary conclusion was drawn. Preparation of destructive earthquakes has always been accompanied with significant electromagnetic radiation and Earth's electromagnetic

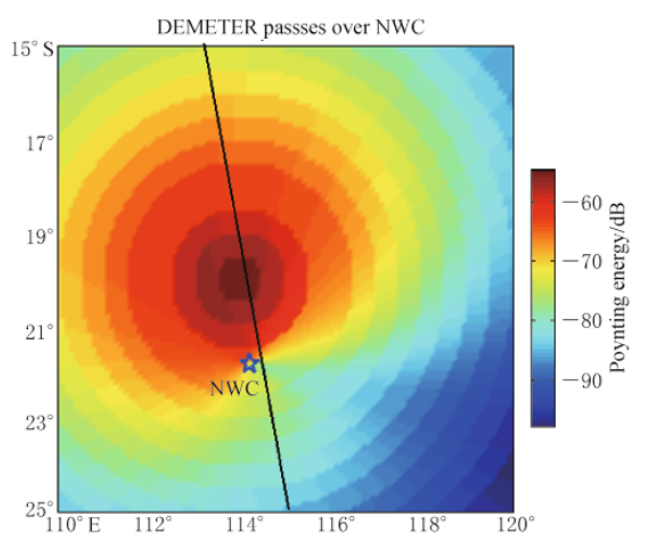

Figure 4 Horizontal mapping of the Poynting flux excited by NWC station (represented by asteria) at 660 $\mathrm{km}$ altitude observed by the DEMETER satellite. 
field disturbance. The additional electromagnetic emission can propagate from the earthquake focus upward to the ground and then into the ionosphere. Ionospheric changes around the earthquakes had been found and reported by lots of case studies.

\section{Recent studies of seismo-ionosp- heric disturbance in China}

In the last few years, scientists did a lot of case studies on the seismo-ionospheric disturbance, such as 1999 Chi-Chi event (Liu et al., 2001), 2005 Sumatra event (Liu et al., 2006), 2008 Wenchuan event (Li et al., 2009; Pulinets et al., 2010). They mainly used DEMETER satellite data as well as ground-based GPS and ionosounding data (Pulinets, 1998; Pulinets and Legen'ka, 2003; Parrot et al., 2006). In China, the researches mainly focus on the $M \geq 6$ earthquakes in Chinese mainland and $M \geq 7$ in all over the world. Some important results were reported.

\subsection{Low-frequency electromagnetic distur- bance}

The main parameters of seismo-electromagnetic precursors include geomagnetic field, telluric field, electromagnetic radiation, plasma disturbance, energetic particle disturbance and so on. A large amount of observations and theoretical simulation results have confirmed that seismogenic radiations have a very wide frequency band. There are a lot of observations of 0.1 $\mathrm{Hz}$ to tens of $\mathrm{kHz}$ bands with electromagnetic field intensity, phase and other anomalistic changes before earthquakes. The ground-based observations show that the amplitude of magnetic field anomaly is about 10
$\mathrm{nT}$, sometimes larger than $100 \mathrm{nT}$ before strong earthquake. The amplitude of electric anomaly is about tens of $\mathrm{mV} / \mathrm{km}$ up to hundreds of $\mathrm{mV} / \mathrm{km}$. The abnormal low frequency electromagnetic radiation is $1-10 \mathrm{mV} / \mathrm{km}$ generally (Ding et al., 2006, 2011).

Our group analyzed the low-frequency electromagnetic disturbance for some large earthquakes using DEMETER data, for example, Sumatra event in 2005 (Zhang et al., 2010b), Wenchuan event in 2008 (Zhang et al., 2009a, d, e, 2010a), Chile events in 2007 and 2010 (Zhang et al., 2009c, 2011; Liu et al., 2011), Yutian event in 2008 (Zhang et al., 2009b). Figure 5 shows the precursors before Wenchuan event (Zhang et al., 2009e). Based on the electric field power spectrum density (PSD) recorded by DEMETER satellite, the anomalies before Wenchuan earthquake were extracted and analyzed. The background spectrum of VLF electric field during two years at $31^{\circ} \mathrm{N}$ above the Wenchuan $M 8$ earthquake in Sichuan were extracted from revisited features of satellite orbits. From the electric field spectra at all frequency points recorded by all ascending orbits at local nighttime within a distance of $2000 \mathrm{~km}$ to Wenchuan epicenter during 1 April to 12 May, 2008, it was shown that in one week before the earthquake, that is 6 to 10 May (35th to 40th day in Figure 5), the electric field PSD increased apparently at the band of 2-6 kHz. While anomalous space distributes in a large area to the south of the epicenter.

From the phenomena reported, the main characteristics of ionospheric electromagnetic disturbances related to earthquakes were summarized.

1) Frequency range of anomalies. Seismoelectromagnetic anomalies appeared at $140 \mathrm{~Hz}$ and (partly at $450 \mathrm{~Hz}$ on more than 100 case studies by
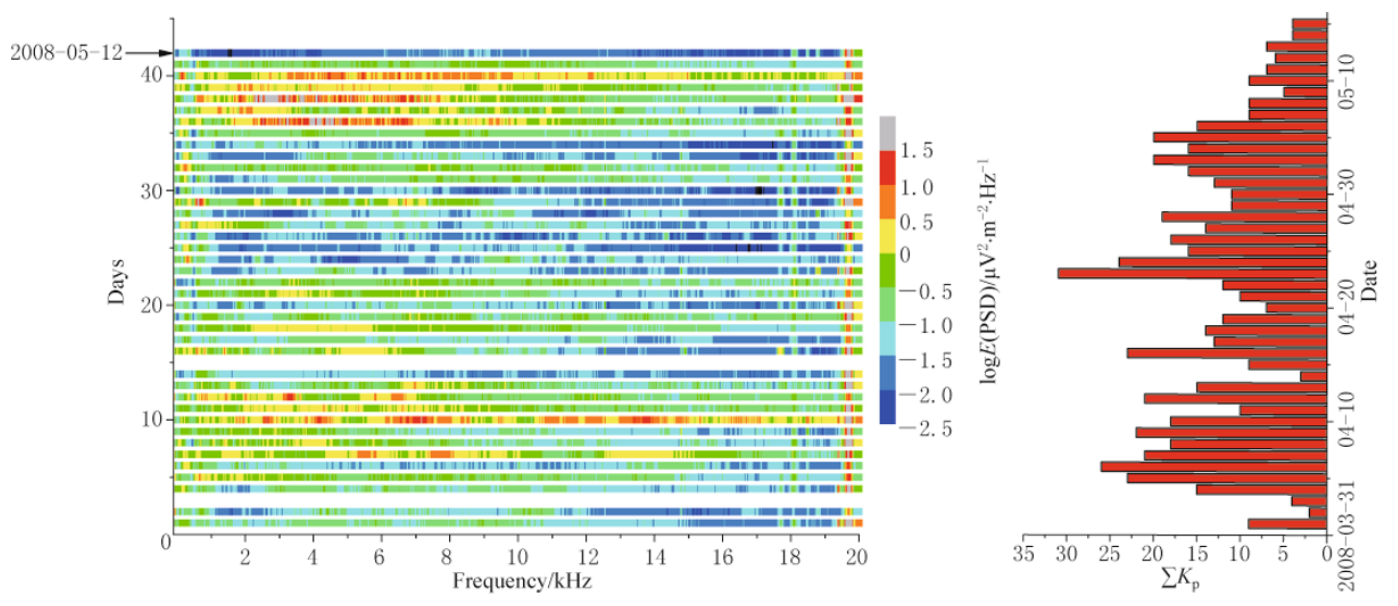

Figure 5 The abnormal of VLF electric field spectrum. 
Russian scientists (e.g., Larkina et al., 1989). Considering the findings of other scientists, anomalies occurred mainly in the ULF/ELF/VLF bands. But high frequency electromagnetic anomalies were also reported in recent years.

2) Amplitude of anomalies. Assuming SNR (signal noise ratio) $>3$ is the threshold to consider an anomaly as earthquake precursor, PSD of geomagnetic emissions was usually greater than $0.3 \mathrm{pt} / \mathrm{Hz}^{1 / 2}$ at frequencies of 100-500 Hz. Perpendicular vector of atmospheric electric field changed more intensively, up to $3-7 \mathrm{mV} / \mathrm{km}$, while changes in components of magnetic field were around $3 \mathrm{nT}$.

3) Time characteristics of anomalies. Abnormal electromagnetic emission came forth usually a few hours before earthquakes. 8-hour is an experiential value.

4) Size of perturbed zone. Based on the results of a large number of case studies, the distribution scale of earthquake-induced electromagnetic anomalies was less than $6^{\circ}$ along longitude. The size along latitude depends on magnetic inclination, for example, the size of perturbed zone was about $5^{\circ}$ at the latitude $40^{\circ}$.

5) Applicability range in space. It is impossible to identify seismo-electromagnetic anomalies at high latitude because of the intensive ULF-VLF emissions around polar region. Satellite observations of electromagnetic anomalies are more suitable for low-middle magnetic latitude in earthquake research.

\subsection{Plasma parameters variation}

Ionospheric foF 2 and total electron content (TEC) response before earthquakes in Taiwan of China were analyzed using ground-based GPS and ionosounding data (Liu et al., 2000, 2001, 2004a, b). The results show that plasma parameters usually changed few days before earthquake occurrence.

From DEMETER satellite data, three half orbits near the epicenter of Pu'er M6.2 earthquake on June 3, 2007 in Yunnan province were selected. The revisited orbits of these three orbits in a year before the earthquake were processed. According to the preliminary result, the spatial images of $N_{\mathrm{e}}$ (electron density) showed high values near the epicenter since 30 days prior to the earthquake. A good correlation between anomalies and location of the earthquake in space and time was found, which reflects that these spatial anomalies were indeed concerned with the earthquake (Ouyang et al., 2008). Similar phenomena were also exhibited before 2010 Chile M8.8 earthquake (Liu et al., 2011).

Figure 6 lists the result about 2008 Wenchuan $M 8$ earthquake, which was integrated by multi parameters. On May 9, three days before the earthquake, the TEC inversed by GPS observation, and foF2 obtained by ionosounding all increased largely (Zhang et al., 2009a).

According to the statistical results of plasma

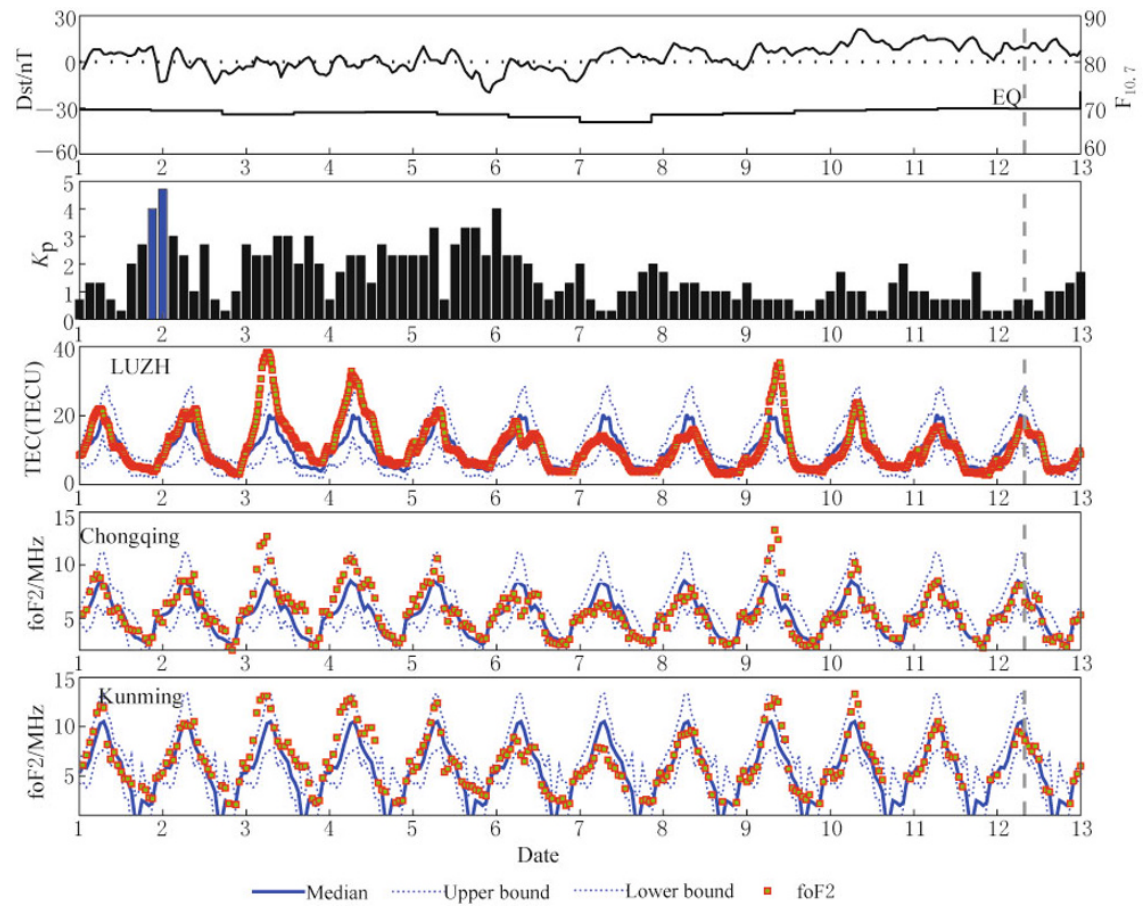

Figure 6 The abnormality on May 9 of local TEC and foF2 before the Wenchuan earthquake on May 12, 2008 (Zhang et al., 2009a). 
disturbance before earthquakes (Pulinets et al., 2003; Liu et al., 2006), and the case studies focusing on the recent earthquakes occurred in China and globe by using DEMETER and GPS data, we may draw the detail characteristics of the plasma variation before earthquake as following:

1) The disturbing parameters related to earthquake activity mainly include TEC, foF $2, \mathrm{Ne}, \mathrm{Ni}$, Te, $\mathrm{Ti}$, and ionospheric height.

2) The anomalies appeared about 15 days before earthquake occurrences. And most of them concentrated on 0-5 days before earthquakes. A few appeared after the earthquake. The duration is about $4-6$ hours, and may be more than 12 hours for some great events.

3) The spatial scale of the ionospheric anomalies may extend to 10 degrees. The ratio of longitude to latitude scale is about $3: 1$. The anomalous area is connected with the latitude of the earthquake.

4) Anomaly amplitude. The range of anomaly amplitude is larger than $15 \%-30 \%$, sometimes $100 \%$ in special region.

\section{The first seismo-electromagnetic satellite in China}

Chinese seismologists have been paying great attention to the development of the space observation techniques in earthquake science. According to the development of space information technology, the applications of remote sensing in disastrous earthquake, and the requirements of space-ground observation technology for earthquake prevention and disaster mitigation, a comprehensive space-based observation system was proposed to obtain various information from solid Earth using the technologies including visible optical, infrared, synthetic aperture radar, electromagnetism, and gravity measurements (Shen et al., 2007). The system will promote the application of spatial information and improve earthquake prediction research. As the first space-based platform of earthquake stereoscopic monitoring system, China Seismo-Electromagnetic Satellite Mission made a successful progress, which aims to establish a spacebased observation system for detecting the electromagnetic anomalies from the solid Earth and the ionosphere perturbation possibly associated with earthquakes and for improving the research on earthquake prediction.

\subsection{Scientific objectives and mission contents of the first satellite}

Since 1950s, anomalous electromagnetic signals have been discovered prior to the earthquakes and vol- cano eruptions by lots of observations from the Earth surface or satellites. Hypotheses were proposed to explain the formation of the anomalous signals associated with earthquake and volcano activities. Due to the activity of geomagnetism, the signals from the earthquake and volcano activities could transmit up to the regions over the epicenters and the regions where satellites pass through.

The first seismo-electromagnetism monitoring satellite is a testing satellite with promising applications in earthquake research and monitoring. Its main scientific objectives are: (1) to obtain the data of the electromagnetic field, the ionosphere, the high-energy particles in China as well as some other parts of the world; (2) to identify and extract the electromagnetic emissions, the plasma, the high-energy particles disturbance information which are related to major earthquake occurrence process; (3) to study the changes in the electromagnetic field, the ionosphere, and the high-energy particles which is related to major earthquake occurrence process and to explore the new way for short-term earthquake monitoring and prediction research; (4) to share data for related scientific research fields and for international cooperation; (5) to check up on performance and reliability of ionospheric detection techniques for the development of space-ground earthquake monitoring system and operation.

According to the scientific objectives, the first satellite concerns various physical parameters including electric field, magnetic field, ionospheric plasma in-situ and profile disturbance, and high energy particle disturbance, etc. The detail parameters are as following:

1) Magnetic field. 3-component magnetic field with frequency band of $\mathrm{DC}-15 \mathrm{~Hz}$ is measured.

2) Induction electromagnetic field. 3-component magnetic field is measured with frequency band of 10 $20 \mathrm{kHz}$; while 3-component electric field with frequency band of $0-3.5 \mathrm{MHz}$.

3) Measurement of plasma and energetic particles in-situ parameters.

Energetic particle spectrum and pitch angle;

Electron and ion temperature;

Electron and ion density;

TEC and electron density profile.

\subsection{Preliminary design of the satellite}

\subsubsection{Orbit parameters}

Different from the usual imaging remote sensing technology, electromagnetic remote sensing is a nonimaging one and acquires the electromagnetic information of the sub-satellite point. For acquiring the earth- 
quake precursor information as much as possible, the orbital span can not be too wide. Based on the recent study results of ionospheric detection by the electromagnetic satellite and theoretical simulation, space anomaly scale would be hundreds of kilometers over the $M_{\mathrm{S}} 7.0$ earthquake. So, the orbital span should less than 1000 $\mathrm{km}$ in every revisiting period. To meet the requirements, we will control the orbital span to be about $5^{\circ}$, which make sure at least one track over the earthquake zone.

The orbit parameters are as following:

1) Orbital span was set to about $5^{\circ}$ between two closest orbits during a revisit period, so that at least one track can be ensured in $10^{\circ}$ scale relative to the future earthquake region.

2) The orbit style is set as push-broom day by day in the revisiting orbit span, which will achieve the biggest chance to get the precursor information from more than one track about one earthquake.
3) Revisiting period is 5 days.

The main orbit parameters of the first electromagnetic satellite are listed in Table 1.

Table 1 Main orbit parameters of the first satellite in China

\begin{tabular}{l|l} 
Orbit type & $\begin{array}{c}\text { Sun synchronous, circular } \\
\text { and polar orbit } \\
\text { about } 500 \\
\text { Altitude/km }\end{array}$ \\
Inclination/ ${ }^{\circ}$ & about 98 \\
Orbit period/min & about 97 \\
Local time of descending node & $14: 00 \mathrm{pm}$ \\
Revisiting cycle/d & 5 \\
\hline
\end{tabular}

\subsubsection{Satellite platform}

The satellite will adopt CAST-2000 common platform. Figure 7 shows the configuration of the satellite, and Table 2 lists the main parameters for satellite platform and operation.

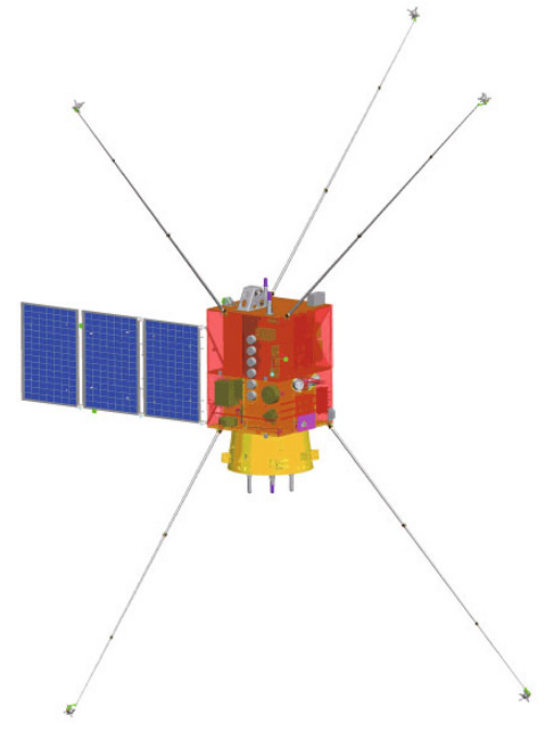

(a)

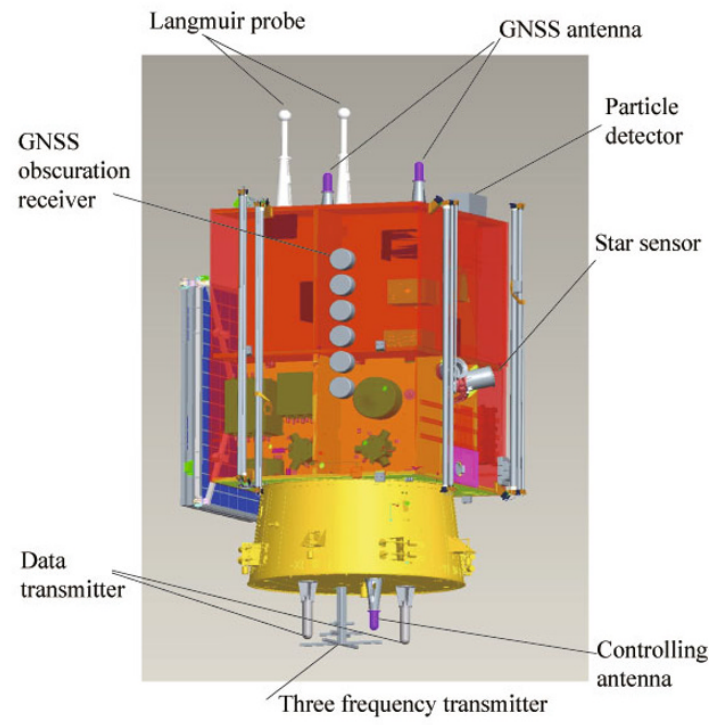

(b)

Figure 7 Configuration of the first electromagnetic satellite in China.

(a) The satellite platform; (b) The position of scientific payloads.

Table 2 Seismo-electromagnetic satellite operations and supports for capacity

\begin{tabular}{ll}
\hline Parameter & Specification \\
\hline Measurement precision of orbit & Real-time orbit determination: better than $100 \mathrm{~m} ;$ non-real-time \\
& orbit determination: better than $50 \mathrm{~cm}$ \\
Attitude control & Pointing accuracy: $\pm 0.5^{\circ} ;$ triaxial stability \\
Storage capacity of satellite & 120 Gbits \\
Data transfer capacity & X-band data download \\
Life time & More than 5 years \\
\hline
\end{tabular}




\subsubsection{The scientific payloads}

As listed in Table 3, the scientific payloads includes search-coiling magnetometer, electric field detec- tor, fluxgate magnetometer, GNSS two-frequency receiver, plasma analyzer, langmuir probe, energetic particle detector, and three-frequency transmitter.

Table 3 Payloads of seismo-electromagnetic satellite

\begin{tabular}{lll}
\hline \multicolumn{1}{c}{ Payload } & \multicolumn{1}{c}{ Physical parameter } & Frequency or range \\
\hline Search coiling magnetometer & 3 components of magnetic field & $10-20 \mathrm{kHz}$ \\
Electric field detector & 3 components of electric field & $\mathrm{DC}-3.5 \mathrm{MHz}$ \\
Fluxgate magnetometer & 3 components of basic magnetic field & $\mathrm{DC}-15 \mathrm{~Hz}$ \\
GNSS occupation receiver & Ionospheric TEC; electron density $N_{\mathrm{e}}$ & \\
& and plasma tomography & $10^{2}-10^{7} \mathrm{~cm}^{-3}$ \\
Plasma analyzer & Ion density & $500-10000 \mathrm{~K}$ \\
& Ion temperature & \\
& Ion components & $10^{2}-10^{7} \mathrm{~cm}^{-3}$ \\
& Ion velocity & $500-10000 \mathrm{~K}$ \\
Langmuir probe & Electron density & $1.5-200 \mathrm{MeV}$ \\
& Electron temperature & $\geq 100 \mathrm{keV}$ \\
Energetic particle detector & Satellite design voltage & $150,450,1066 \mathrm{MHz}$ \\
\hline
\end{tabular}

\section{Conclusions}

Earthquake prediction is one of the most difficult challenges in the world. The progress in monitoring techniques is fundamental for earthquake prediction researches. The reported researches show that electromagnetic and ionospheric precursor monitoring may be one of the effective means of short-temporary-term earthquake prediction. Seismo-electromagnetic precursors and their mechanism are extremely complicated. This paper summarized the main works focusing on seismo-ionospheric coupling and related ionospheric disturbance phenomena before earthquakes in the last few years in China. According to the primary results of theoretical and case studies, electromagnetic and ionospheric precursors may play an effective role to impending earthquakes. The main ideas are as following:

1) The ground and underground electromagnetic waves and emission can propagate or penetrate into the ionosphere according to the lithosphereatmosphere-ionosphere coupling mechanisms. A thermo-electric model was proposed to explain the seismo-electromagnetic effects before earthquakes. A propagation model was put forward to explain the electromagnetic waves into the ionosphere. These theoretical models are useful to explain the seismo-ionospheric disturbance phenomena observed over the earthquake zones.
2) According to the researches on satellites data, ground-based GPS data, and ionosounding data, some statistical features of earthquake-related ionospheric anomalies were found. (1) Major physical parameters include VLF, ELF, ULF electromagnetic fields and waves, TEC, foF2, density and temperature of electronic/ion, ion composition, high energy flux and so on; (2) the ionospheric disturbances usually appear $1-5$ days before earthquakes with a duration of 4-6 hours for plasma, 1-5 hours before earthquakes for electromagnetic wave and high energy particles and often occur in the afternoon of local time; (3) the spatial extent of disturbances distribution may occupy a radius of about $5^{\circ}$, and regular migration of anomalies relative to epicenter, sometimes it has magnetic conjugation effects; (4) anomaly intensity is few to tens of nT for magnetic field, few to hundreds of $\mu \mathrm{V} / \mathrm{m}$ for electric field, relative change is more than $15 \%-30 \%$ for plasma and high energy particle.

3) Observations are the fundament of the earthquake research and prediction. The first seismoelectromagnetic satellite in China was proposed to acquire the earthquake-related ionospheric disturbance. It is planned to launch at the end of 2014. The preliminary design of the satellite will adopt CAST-2000 platform, eight payloads onboard. It is believed that the spacebased monitoring platform will work together with the ground monitoring network to improve the capability 
of capturing seismo-electromagnetic information and to benefit the earthquake monitoring and prediction research.

Acknowledgements This work was carried out by the working group of earthquake-related satellite mission in China, and was kindly supported by French CNES, DEMETER mission center, and Russian scientists from IZMIRAN and IPE. Special thanks are given to Profs. Michel Parrot, Yuri Ruzhin, Sergey Pulinets, Z.Y. Liu, Roberto Battiston and Dr. Dimitar Ouzounov and the anonymous reviewers for their help. This work is funded by National Key Technology R\&D Program in the 11th Five Year Plan of China (2008BAC35B00), and the international cooperation project (2009DFA21480).

\section{References}

Cussac T, Clair M, Ultré-Guerard P, Buisson F, LassalleBalier G, Ledu M, Elisabelar C, Passot X and Rey N (2006). The Demeter microsatellite and ground segment. Planet Space Science 54: 413-427.

Chmyrev V M, Isaev N V, Serebryakova O N, Sorokin V M and Sobolev Y P (1997). Small-scale plasma inhomogeneities and correlated ELF emissions in the ionosphere over an earthquake region. J Atmos Solar-Terr Phys 59: 967-974.

Davies K and Baker D M (1965). Ionospheric effects observed around the time of the Alaska earthquake of March 28 1964. J Geophys Res 70: 172-179.

Ding J H, Lu Z Y and Yu S R (2011). A Brief Treatise on Seismomagnetism. Publishing House of Chinese University of Sciences and Technology, Hefei, 490pp (in Chinese).

Ding J H, Shen X H and Pan W Y (2006). Research progress of seismoelectromagnetic precursors. Chinese $J$ Radio Science 21(5): 791-801 (in Chinese with English abstract).

Gokhberg M B, Pilipenko V A and Pokhotelov O A (1983). Seismic precursors in the ionosphere. Izv Earth Phys 19: 762-765 (in Russian).

Hegai V V, Kim V P and Nikiforova L I (1997). A possible generation mechanism of acoustic-gravity waves in the ionosphere before strong earthquakes. J Earthq Predict Res 6: 584-589.

Isaev N V and Serebryakova O N (2001). Electromagnetic and plasma effects of seismic activity in the Earth ionosphere. Chem Phys Reports 19(6): 1 177-1 188.

Klimenko M V, Klimenko V V, Zakharenkova I E, Pulinets S A, Zhao B and Tzidilina M N (2011). Formation mechanism of great positive disturbances prior to Wenchuan earthquake on May 12, 2008. Adv Space Res 48: 488-499.

Lagouttea D, Brochota J Y, de Carvalhoa D, Elie F, Harivelo
F, Hobara Y, Madrias L, Parrot M, Pincon J L, Berthelier J J, Peschard D, Seran E, Gangloff M, Sauvaud J A, Lebreton J P, Stverak S, Travnicek P, Grygorczuk J, Slominski J, Wronowski R, Barbier S, Bernard P, Gaboriaud A and Walluth J M (2006). The DEMETER science mission centre. Planet Space Sci 54: 428-440.

Larkina V I, Migulin V V and Molchanov O A (1989). Some statistical results on very low frequency radio wave emissions in the upper ionosphere over earthquake zones. Phys Earth Planet Inter 57: 100-109.

Li J Y, Meng G J, Wang M, Liao H and Shen X H (2009). Investigation of ionospheric TEC changes related to the 2008 Wenchuan earthquake based on statistic analysis and signal detection. Earthquake Science 22: 545-553.

Liu J, Wan W X, Huang J P, Zhang X M, Zhao S F, Ouyang X Y and Zeren Z (2011). Electron density perturbation before Chile M8.8 earthquake. Chinese J Geophys 54(11): 2 717-2 725 (in Chinese with English abstract).

Liu J Y, Chen Y I, Chuo Y J and Tsai H F (2001). Variations of ionospheric total electron content during the Chi-Chi earthquake. Geophys Res Lett 28: 1 383-1 386.

Liu J Y, Chen Y I, Pulinets S A, Tsai Y B and Chuo Y J (2000). Seismo-ionospheric signatures prior to $M>6.0$ Taiwan earthquakes. Geophys Res Lett 27: 3 113-3 116.

Liu J Y, Chuo Y J, Shan S J, Tsai Y B, Chen Y I, Pulinets $\mathrm{S}$ A and Yu S B (2004a). Pre-earthquake ionospheric anomalies registered by continuous GPS TEC measurements. Ann Geophys 22: 1 585-1 593.

Liu J Y, Tsai Y B, Ma K F, Chen Yun-Ing, Tsai H F and Lin C H (2006). Ionospheric GPS total electron content (TEC) disturbances triggered by the 26 December 2004 Indian Ocean tsunami. J Geophys Res 111: A05304.

Liu J Y, Chen Y I, Huang H K and Lin Y H (2004b). Ionospheric foF2 and TEC anomalous days associated with $M \geq 5$ earthquake in Taiwan during 1997-1999. TAO 15(3): 371-384.

Molchanov O, Fedorov E, Schekotov A, Gordeev E, Chebrov V, Surkov V, Rozhnoi A, Andreevsky S, Iudin D, Yunga S, Lutikov A, Hayakawa M and Biagi P F (2004). Lithosphere-atmosphere-ionosphere coupling as governing mechanism for preseismic short-term events in atmosphere and ionosphere. Nat Hazards Earth Syst Sci 4: $757-767$.

Molchanov O A, Hayakaya M and Rafalsky V A (1995). Penetration characteristics of electromagnetic emissions from an underground seismic source into the atmosphere, ionosphere, and magnetosphere. J Geophys Res 100(A2): 1 691-1 712.

Ouyang X Y, Zhang X M, Shen X H, Liu J, Qian J D, Cai J A and Zhao S F (2008). Ionospheric $N_{\mathrm{e}}$ disturbances before $2007 \mathrm{Pu}$ 'er, Yunnan, China, earthquake. Earthquake Science 21(4): 425-437.

Parrot M (1995). Use of satellites to detect seismoelectromagnetic effects. Adv Space Res 15(11): 27-35. 
Parrot M and Lefeuvre F (1989). Correlation between GEOS VLF emissions and earthquakes. Ann Geophys 3: 737748.

Parrot M, Achache J, Berthelier J J, Blanc E, Deschamps A, Lefeuvre F, Menvielle M, Plantet J L, Tarits P and Villain J P (1993). High frequency seismo-electromagnetic effects. Phys Earth Planet Inter 77: 65-83.

Parrot M, Benoist D, Berthelier J, Błęecki J, Chapuis Y, Colin F, Elie F, Fergeau P, Lagoutte D, Lefeuvre F, Legendre C, Lévêque M, Pinçon J L, Poirier B, Seran H-C and Zamora P (2006). The magnetic field experiment IMSC and its data processing onboard DEMETER: Scientific objectives, description and first results. Planet Space Science 54: 441-455.

Pulinets S and Boyarchuk K (2004). Ionospheric Precursors of Earthquakes. Springer, Berlin, 315pp.

Pulinets S and Ouzounov D (2011). LithosphereAtmosphere-Ionosphere Coupling (LAIC) model - An unified concept for earthquake precursors validation. $J$ Asian Earth Sci 41: 371-382.

Pulinets S A (1998). Strong earthquakes prediction possibility with the help of topside sounding from satellites. $A d v$ Space Res 21(3): 455-458.

Pulinets S A (2004). Ionospheric precursors of earthquakes; recent advances in theory and practical applications. Terr Atmos Ocean Sci 15(3): 413-415.

Pulinets S A (2009). Physical mechanism of the vertical electric field generation over active tectonic faults. Adv Space Res 44: 767-773.

Pulinets S A and Legen'ka A D (2003). Spatial-temporal characteristics of large scale distributions of electron density observed in the ionospheric F-region before strong earthquakes. Cosmic Research 41(3): 221-229.

Pulinets S A, Alekseev V A, Legen'ka A D and Khegai V V (1997). Radon and metallic aerosols emanation before strong earthquakes and their role in atmosphere and ionosphere modification. Adv Space Res 20: 2 173-2 176.

Pulinets S A, Bondur V G, Tsidilina M N and Gaponova M $\mathrm{V}$ (2010). Verification of the concept of seismoionospheric relations under quiet heliogeomagnetic conditions, using the Wenchuan (China) earthquake of May 12, 2008, as an example. Geomagnetism and Aeronomy 50(2): 231-242.

Pulinets S A, Boyarchuk K A, Hegai V V, Kim V P and Lomonosov A M (2000). Quasielectrostatic model of atmosphere-thermosphere-ionosphere coupling. Adv Space Res 26(8): 1 209-1 218.

Pulinets S A, Khegai V V, Boyarchuk K A and Lomonosov A M (1998). Atmospheric electric field as a source of ionospheric variability. Physics-Uspekhi 41(5): 515-522.

Pulinets S A, Legen'ka A D and Alekseev V A (1994). Pre-earthquakes effects and their possible mechanisms. In: Kikuchi H ed. Dusty and Dirty Plasmas, Noise and Chaos in Space and in the Laboratory. Plenum Publishing, New York, 545-557.
Pulinets S A, Legen'ka A D, Gaivoronskaya T V and Depuev V K (2003). The main phenomenological features of ionospheric precursors of strong earthquakes. J Atm Solar Terr Phys 65: 1 337-1 347.

Ruzhin Y Y and Larkina V I (1996). Magnetic conjugation and a time coherency of seismoionosphere VLF bursts and energetic particles. In: Proceedings of International Wroclaw Symposium on Electromagnetic Compatibility. June 25-28, Poland, Wroclaw, 645-648.

Ruzhin Y Y, Larkina V I and Depueva A K (1998). Earthquake precursors in magnetically conjugated ionosphere regions. Adv Space Res 21: 525-528.

Shalimov S L and Gokhberg M B (1998). Lithosphereionosphere coupling mechanism and its application to earthquake in Iran on June 20 1990. A review of ionospheric measurements and basic assumptions. Phys Earth Planet Inter 105: 211-218.

Shen J, Shen X and Liu Q (2009). The thermo-electric effect of natural minerals and its potential in application in earthquake prediction research. Bulletin of Minerals, Rocks and Geochemistry 28(3): 301-307 (in Chinese with English abstract).

Shen J, Shen X and Liu Q (2010a). The thermoelectric effect of magnetite: a new model for abnormal geo-electricity from the formation and occurrence of earthquake. J Mineral Petrol 30(4): 21-27 (in Chinese with English abstract).

Shen J F, Shen X H, Liu Q and Ying N (2010a). The thermoelectric effect of magnetite and mechanism of geo-electric abnormalities during earthquake. Geoscience Frontiers 1(1): 99-104 (in Chinese with English abstract).

Shen X H, Shan X J, Wu Y, Zhang J F, Kang C L, Ding J H, Qian J D, Yang D M, Du X B and Wang L W (2007). Current status of remote sensing application in earthquake science and the framework of Chinese seismo-related satellite mission. Recent Developments in World Seismology (8): 38-45 (in Chinese with English abstract).

Sorokin V M, Yaschenko A K and Hayakawa M (2007). A perturbation of DC electric field caused by light ion adhesion to aerosols during the growth in seismic-related atmospheric radioactivity. Nat Hazards Earth Syst Sci 7: $155-163$.

Takeuchi B, Lau W S and Freund F T (2004). Current and surface potential induced by stress-activated positive holes in igneous rocks. Phys Chem Earth 31(4-9): 240-247.

Zhang X, Shen X, Liu J, Ouyang X, Qian J and Zhao S (2010a). Ionospheric perturbations of electron density before the Wenchuan earthquake. International Journal of Remote Sensing 31(13): 3 559-3 569.

Zhang X, Zeren Z, Parrot M, Battiston R, Qian J and Shen X (2011). ULF/ELF ionospheric electric field and plasma perturbations related to Chile earthquakes. Adv Space 
Res 47: 991-1 000.

Zhang X M, Ding J H, Shen X H, Wang M, Liu J, Yu S R, Wang Y L and Ouyang X Y (2009a). Electromagnetic perturbations before Wenchuan $M 8$ earthquake and stereo electromagnetic observation system. Chinese $J$ Radio Science 24(1): 1-8 (in Chinese with English abstract).

Zhang X M, Liu J, Shen X H, Parrot M, Qian J D, Ouyang X Y, Zhao S F and Huang J (2010b). Ionospheric perturbations associated with the M8.6 Sumatra earthquake on 28 March 2005. Chinese J Geophys 53(3): 567-575.

Zhang X M, Qian J D, Ouyang X Y, Cai J A, Liu J, Shen $\mathrm{X} \mathrm{H}$ and Zhao S F (2009b). Ionospheric electro-magnetic disturbances prior to Yutian 7.2 earthquake in Xinjiang. Chin Space Sci 29(2): 213-221.

Zhang X M, Qian J D, Ouyang X Y, Shen X H, Cai J A and Zhao S F (2009c). Ionospheric electromagnetic perturbations observed on DEMETER satellite before Chile M7.9 earthquake. Earthquake Science 22: 251-255.

Zhang X M, Shen X H, Liu J, Ouyang X Y, Qian J D, and Zhao S F (2009d). Analysis of ionosphere plasma perturbations before Wenchuan earthquake. Nat Hazards Earth Syst Sci 9: 1 259-1 266.

Zhang X M, Shen X H, Ouyang X Y, Cai J A, Huang J P, Li$\mathrm{u} \mathrm{J}$ and Zhao S F (2009e). Ionosphere VLF electric field anomalies before Wenchuan M8 earthquake. Chinese $J$ Radio Science 24(6): 1 024-1 032 (in Chinese with English abstract).

Zhao S F, Shen X H, Pan W Y, Zhang X M and Liao L (2010). Penetration characteristics of VLF wave from atmosphere into lower ionosphere. Earthquake Science 23: $275-282$. 